\title{
Level of Labor Pain, Level of Labor Pain Behaviors, and Cultural Pain Behaviors among First-Time Indonesian Muslim Mothers
}

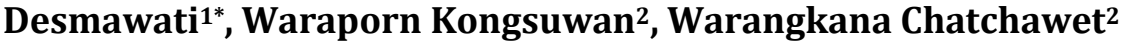 \\ ${ }^{1}$ Faculty of Health Science, Universitas Pembangunan Nasional Veteran Jakarta, Jakarta, Indonesia \\ ${ }^{2}$ Faculty of Nursing, Prince of Songkla University, Hatyai, Thailand \\ Email: *desmawati.campay@gmail.com
}

How to cite this paper: Desmawati, Kongsuwan, W. and Chatchawet, W. (2021) Level of Labor Pain, Level of Labor Pain Behaviors, and Cultural Pain Behaviors among First-Time Indonesian Muslim Mothers. Open Journal of Obstetrics and Gynecology, 11, 27-39.

https://doi.org/10.4236/ojog.2021.111004

Received: December 3, 2020

Accepted: January 19, 2021

Published: January 22, 2021

Copyright $\odot 2021$ by author(s) and Scientific Research Publishing Inc. This work is licensed under the Creative Commons Attribution International License (CC BY 4.0).

http://creativecommons.org/licenses/by/4.0/

\begin{abstract}
Background: Many factors influence the expressions of pain in primiparous women aside from contractions of the uterus. Objective: This study aimed to describe the level labor pain, level of labor pain behaviors based on cultural pain behaviors at $3-4 \mathrm{~cm}$ of cervical dilation or the beginning of the active phase of labor among primiparous Muslim women in Indonesia. Methods: This was a study with 42 primiparous Muslim women who gave birth in the labor room at Bhinneka Bhakti Husada Hospital and Community Health Center Pamulang, Indonesia from June until January 2017. The women were asked to describe on a $100 \mathrm{~mm}$ Visual Analogue Scale the intensity of level of labor pain in their abdomen during the last contractions at $3-4 \mathrm{~cm}$ of cervical dilation, and Pain Behaviors Observation Scale to observe pain behaviors. Descriptive statistics were used to analyze the data. Results: The findings showed that the mean score of level of labor pain at $3-4 \mathrm{~cm}$ of cervical dilation was $86.38(\mathrm{SD}=4.47)$ and most participants experienced high level of labor pain (97.6\%). The expression of cultural labor pain behaviors including saying praises to Allah, Asma' aul husna, reciting the Qur'an, sholawat.
\end{abstract}

\section{Keywords}

Level of Labor Pain, Pain Behaviors, Cultural Pain Behaviors, Primiparous

\section{Introduction}

Labor pain is the feeling of hurt from uterine contractions and accepted as a part of childbirth [1]. Labor pain has always haunted pregnant women, especially in primiparous. Pain can be subjective and influenced by many factors, for instance 
uterine contractions, cervical dilation, and parity [1]-[7]. Women respond to labor pain uniquely and differently depending on level or severity of labor pain, experience, coping strategy, motivation to endure the pain, and culture evaluation. Culture has a strong role in responses to the labor pain [8].

Pain behavior is how pain is expressed by a person and depends on the intensity and frequency of the pain [9]. When women have severe labor pain, they tend to have uncontrolled or inappropriate behaviors, such as, restlessness, crying out, sobbing, uncontrolled breathing, grimacing, wincing, showing desperation, and often asking for help from other people or God. These behaviors are also associated with beliefs in spiritual and cultural factors (cultural pain) [3] [4] [8].

Indonesia comprising many ethnic and culture that each ethnic has its own unique and has various responses to pain. Bataknese more expressive compared to other ethnic, such as "stand up" whenever they are pain and suffering because it was shameful if not family member find out that they are pain [8]. There have been no studies conducted to describe the labor pain severity and pain behaviors among Indonesian women especially primiparous women.

The first experience of labor pain was found to be severe for primiparous women. The stronger stimulation of the pelvic and cervical nociceptors by the fetal head and cause greater pain in primiparous women [10] [11]. Severe labor pain has negative impacts on the mother and fetus. Severe pain during labor was reported to disturb the maternal autonomic functions and caused the release of catecholamine resulting in abnormal labor and fetal distress [12] [13] [14] [15], inhibition of uterine activity, abnormal uterine contractions, prolonged labor, and increased risk of intra-partum problems [14] [15] [16].

Most primiparous women (75\%) reported that their pain during childbirth was severe or intolerable [17]. Almost $50 \%$ of primiparous women complained of moderate pain $(49.06 \%)$ and $96 \%$ of the women complained that pain was felt in the lower abdomen, then hip and thighs. Also, $90 \%$ of primiparous women felt cramping and $88 \%$ felt dullness [18]. The severity of labor pain was reported to be severe by $37 \%$, moderate by $52.9 \%$, and mild by $10.1 \%$ of primiparous women in labor. This is higher than $20.7 \%$ of multiparous women who reported severe pain [10]. Besides the parity, uterine contractions, and cervical dilation, many factors from demographic and obstetric data can influence labor pain [19].

Previous studies reported that severe pain during labor was also influenced by the age of the mother [4] [10], ruptured of the membranes [6], painful menstruation, weight of the fetus, weight/height ratio of the mother, time of birth [4] [20], race, and ethnicity [21] [22]. Thus, describing the demographic and obstetric data, knowing the level of labor pain, and understanding the behaviors of women with different cultures can help nursing-midwives to provide culturally appropriate interventions that are important to prevent complications in the mothers and their fetus [23]. Therefore, the purpose of this study was to describe labor pain levels, labor pain behaviors, cultural pain behaviors among first-time (primiparous) Indonesian Muslim mothers. 


\section{Research Question}

What was the level of labor pain, level of labor pain behaviors, and cultural pain behaviors manifested as behaviors among primiparous Indonesian Muslim mothers at the beginning of the active phase of labor?

\section{Methods}

\subsection{Sample, Setting, Instrumentation}

This study was conducted in primiparous Muslim women at the antenatal clinics and labor rooms at Community Health Center (CHC) Pamulang and Bhinneka Bhakti Husada (BBH) Hospital in Indonesia. Currently, the Indonesian government uses the universal public health insurance program called the Badan Penyelenggara Jaminan Sosial. All pregnant women should register at the CHC for main services and take all administrative correspondence. The $\mathrm{BBH}$ Hospital and CHC Pamulang provide similar standardized care for normal delivery. The settings and context of care for birth in the two places use the same services and have the same levels of professional support. In this study, the participants received only usual care without any training concerning pain control.

The participants consisted of 42 primiparous Muslim women randomly selected who met inclusion criteria from June to January 2017. A sample calculation using Cohen formula with effect size $=0.64, \alpha=0.05$, and power $=0.80$. The sample criteria were normal gestation for birth, not coming to the labor room at $>4 \mathrm{~cm}$ of cervical dilation (cd), normal fetal heart rate, latent phase no more than 12 hours, cephalic presentation, estimated fetal weight of 2500 to 4000 grams, progress of labor not less than 3 hours, absence of health complications for the mother or fetus, and have no contraindication for vaginal delivery. Primiparous Muslim women who came to the labor room were asked to participate in this study and the researcher obtained informed consent. They were provided an explanation of the study and they signed the informed consent if they agreed to participate in this study. They were free to withdraw from this study at any time without any consequences. After that, the researcher collected the demographic and obstetric data. Labor pain was measured in the labor room at the active phase of labor ( $3-4 \mathrm{~cm}$ of cervical dilation). The labor pain behaviors and cultural pain behaviors of the primiparous Muslim women were recorded and observed by researcher during uterine contractions at the active phase of labor (3 - $4 \mathrm{~cm}$ of cervical dilation).

The Demographic Data Questionnaire and Obstetric Data Questionnaire were used to record the demographic and obstetric data. A visual analogue scale (VAS) was used to measure the levels of labor pain and the Pain Behaviors Observation Scale was used to measure other pain parameters. The VAS was a 0 to $100 \mathrm{~mm}$ line (from no pain to worst imaginable pain). Over $60 \mathrm{~mm}$ on the VAS indicates severe pain, moderate pain ranges from $40-60 \mathrm{~mm}$ and mild pain is under $40 \mathrm{~mm}$. The higher scores implied the higher level of pain. The parameters of pain behaviors used an observation scale including vocalization, body 
movement, breathing, facial expression, and communication that was developed by Baosoung (1983) [24]. Since this instrument is general, additional pain behavior parameters, such as, spiritual and cultural factors among primiparous Muslim women in Indonesia were also observed. The demographic data included questions related to age, education, employment, ethnicity, and family income per month. The obstetrics data were comprised of the number of times the mother received ANC, pain menstruation, gestational age at birth, mother's weight and height, received artificial or spontaneous rupture of membranes, characteristics of amniotic fluid, baby weight, Apgar score at 1 minute, and Apgar score at 5 minutes after the baby was born.

\subsection{Ethical Considerations}

The Institutional Review Board (IRB) of the Faculty of Nursing, Prince of Songkla University, Thailand (code: MOE 0521.1.05/1663) and the ethics committees at the Bhinneka Bhakti Husada Hospital, and University of Pembangunan Nasional Veteran Jakarta, Indonesia approved this study.

\subsection{Data Analysis}

Descriptive statistics were used to analyze the data on demographics, obstetrics, level of labor pain, and labor pain behaviors of primiparous Muslim women in Indonesia during uterine contractions. Data were cleared and analyzed by univariate analysis with the level of statistical significance set at $p=0.05$.

\section{Results}

\subsection{Demographic Data of Participants}

Table 1 shows the demographic characteristics of the primiparous Muslim women who participated in this study. The largest ethnic percentages of the

Table 1. Demographic data $(n=42)$.

\begin{tabular}{cccc}
\hline Variables & M (SD) & $\mathrm{n}$ & $\%$ \\
\hline Age (years) & $23.14(3.7)$ & & \\
Ethnic background & & & \\
Betawinese, Sundanese & 33 & 78.6 \\
Javanese, Minangnese, Bataknese & 9 & 21.4 \\
Educational level & & \\
Senior and junior high school & 35 & 83.3 \\
Diploma and bachelor & 7 & 16.7 \\
Occupation & & \\
Unemployed & 31 & 73.8 \\
Employed & & 11 & 26.2 \\
Family income/month (IDR) & $3,809,520(1,909,380)$ & & \\
\hline
\end{tabular}

$\mathrm{M}=$ Mean $; \mathrm{SD}=$ Standard Deviation; IDR = Indonesian Rupiah. 
primiparous Muslim women were Betawinese and Sundanese which are the original ethnicities of Jakarta-Banten. The average age was 23.14 years old and more than half of the participants completed senior high school and junior high school levels. Most of the pregnant women were not working and reported that their family monthly incomes were a mean of 3,809,520 IDR.

\subsection{Obstetric Data of Participants}

Table 2 presents the obstetric data of the primiparous Muslim women who participated in this study. The average number of times to receive ANC was 10.2 times. Nearly all participants had not experienced painful menstruation and did not have health problems during this pregnancy. The average age of gestation at birth was 39.2 weeks of pregnancy. The means of the mother's weight and height at birth were $68 \mathrm{kgs}$ and $153.7 \mathrm{cms}$, respectively. The majority of the women did not receive artificially ruptured membranes or spontaneous rupture of membranes $(81 \%)$. In more than half of the women, amniotic fluid was clear meconium and in the rest the amniotic fluid was mild to thick meconium. The mean Apgar scores at one and five minutes after birth were 8.79 and 9.79, respectively. The average newborn weight was 3069.05 grams.

\subsection{Level of Labor Pain during the Active Phase of Labor}

The mean score of labor pain at $3-4 \mathrm{~cm}$ of cervical dilation was $86.38(\mathrm{SD}=$ 4.47). The levels of labor pain are described in Table 3.

Table 2. Obstetric data $(n=42)$.

\begin{tabular}{|c|c|c|c|}
\hline Characteristics & $\mathrm{M}(\mathrm{SD})$ & $\mathrm{n}$ & $\%$ \\
\hline Number of time receiving ANC & $10.2(1.8)$ & & \\
\hline \multicolumn{4}{|l|}{ Painful menstruation } \\
\hline No & & 38 & 90.5 \\
\hline Yes & & 4 & 9.5 \\
\hline Gestational age at birth (weeks of pregnancy) & $39.2(0.9)$ & & \\
\hline Mother's Weight & $68(6)$ & & \\
\hline Mother's Height & $153.7(3.2)$ & & \\
\hline \multicolumn{4}{|l|}{ Receive artificial rupture of membrane } \\
\hline No & & 34 & 81 \\
\hline Yes & & 8 & 19 \\
\hline \multicolumn{4}{|l|}{ Characteristics of amniotic fluid: } \\
\hline Clear & & 27 & 64.3 \\
\hline Mild & & 10 & 23.8 \\
\hline Thick & & 5 & 11.9 \\
\hline Baby weight & $3069.05(307.05)$ & & \\
\hline Apgar score at 1 minute & $8.79(0.41)$ & & \\
\hline Apgar score at 5 minutes & $9.76(0.43)$ & & \\
\hline
\end{tabular}

$\mathrm{M}=$ Mean; $\mathrm{SD}=$ Standard Deviation . 
Table 3. Level of labor pain $(n=42)$.

\begin{tabular}{ccc}
\hline \multirow{2}{*}{ Levels of labor pain } & \multicolumn{2}{c}{ Level of labor pain } \\
\cline { 2 - 3 } & $\mathrm{N}$ & $\%$ \\
\hline Moderate (40 to 60 mm of VAS) & 1 & 2.4 \\
High (>60 to 100 mm of VAS) & 41 & 97.6 \\
\hline
\end{tabular}

VAS $=$ Visual Analogue Scale

\subsection{Level of Pain Behaviors during Uterine Contraction}

The behaviors of the participants were the observable behaviors that the primiparous Muslim women exhibited in response to labor pain. The labor pain behaviors were at high and moderate levels (Table 4).

\subsection{Cultural and Spiritual of Pain Behavior}

Other communications of pain behaviors also were observed by researcher with observing the mother's behaviors during uterine contractions at the active phase of labor ( $3-4 \mathrm{~cm}$ of cervical dilation). These behaviors included cultural and spiritual pain behaviors because religion affects cultures. The participants were asking for help from God (Allah), such as saying praises to Allah, calling out the name of Allah (Asma'aul husna), and reciting the Qur'an, sholawat.

\section{Discussion}

This study found that the average age of the mothers was 23.14 years old, which is in the age range recommended for pregnancy and childbirth (20 - 35 years old) [19]. Mothers older than 35 years old have increased risks of complications such as endometrium problems related to labor pain and the progress of labor [20] [21]. A mother less than 20 years old has not fully matured in regards to reproduction which can often result in complications of childbirth and is also related to pain [21]. This study also suggested that older primiparous Muslim women who were 35 years old and above were more likely to experience lower labor pain compared to younger primiparous Muslim women aged 19 to 35 years old because the old women have good coping mechanism to solve the labor pain. This finding was the same as a previous study in India which reported that labor pain was found to be more severe in younger women compared to older women [25]. Also, similar to a study in European countries done by Sheiner et al. [26], a higher pain threshold was reported in advancing age, thus pain perception decreased with increased age.

Ethnicity and race are believed to play a role in response to labor pain. Previous studies found that non-Hispanic white patients experienced more pain and limited pain control compared with Hispanic black patients. Less pain was reported for black compared with white should be further explored [27] [28]. In this study, the Betawinese and Sundanese are the dominant indigenous people of Jakarta-Banten; however, there are other ethnic groups such as Javanese, Minangnese, and Bataknese because Pamulang's residents are the same as the 
Table 4. Level of pain behaviors by the pain behaviors observation scale $(n=42)$.

\begin{tabular}{|c|c|c|c|c|c|}
\hline No & & Pain behaviors & $\mathrm{n}$ & $\%$ & Level \\
\hline \multirow{3}{*}{1} & \multirow{3}{*}{ Vocalization } & crying out, sobbing & 25 & 59.52 & \multirow{2}{*}{ high } \\
\hline & & sighing, moaning & 16 & 38.09 & \\
\hline & & no sound & 1 & 2.38 & moderate \\
\hline \multirow{3}{*}{2} & \multirow{3}{*}{ Body movement } & restlessness & 23 & 54.76 & \multirow{2}{*}{ high } \\
\hline & & protection movement & 18 & 42.86 & \\
\hline & & relaxed movements & 1 & 2.38 & moderate \\
\hline \multirow{3}{*}{3} & \multirow{3}{*}{ Breathing } & irregularly but try to control breathing & 25 & 59.52 & \multirow{2}{*}{ high } \\
\hline & & cannot control breathing & 16 & 38.09 & \\
\hline & & good regularly control breathing & 1 & 2.38 & moderate \\
\hline \multirow{3}{*}{4} & \multirow{3}{*}{ Facial expression } & Tense & 25 & 59.52 & \multirow{2}{*}{ high } \\
\hline & & Grimacing & 16 & 38.09 & \\
\hline & & Grimacing & 1 & 2.38 & moderate \\
\hline \multirow{3}{*}{5} & & desperate or often asking for help & 18 & 42.86 & \multirow{2}{*}{ high } \\
\hline & Communication & some complaints of pain or asking for help & 23 & 54.76 & \\
\hline & & no complaint of pain & 1 & 2.38 & moderate \\
\hline
\end{tabular}

residents in the capital city of Jakarta where people come from various provinces in Indonesia. It was shown that the Bataknese were less tolerant of post-operation pain than the Javanese people [22], and approximately half of the Bataknese expressed low pain behaviors. It seems the Batak tradition to be angry and "stand up" whenever they feel pain and suffering and more so with those who are not family members. The presence family as the closest person gives it good assistance psychologically will be able to divert attention from pain and decrease levels stressor [8]. Therefore, a future study is needed to identify the relationship of ethnicity with labor pain in Indonesia.

Labor pain is a necessary and integral part of the life experience. Painful birth in primiparous women is an experience for future labor. This study reported the level of labor pain in primiparous Muslim women in Indonesia. Most of the participants in Indonesia felt severe labor pain which was similar to a previous study in Iran [17] where $75 \%$ of the primiparous women reported that their pain during childbirth was severe or intolerable. However, this result is not the same as another study in Nepal [5] which reported labor pain as severe in $37 \%$, moderate in $52.9 \%$, and mild in $10.1 \%$ of primiparous women in labor. This was possibly explained by the differences in race, ethnicity, and cultural that are influenced by beliefs or spirituality, so that labor pain is subjective and unique.

According to previous studies, the attitudes of labor pain were influenced by cultural factors [28] [29]. Besides ethnicity, there were cultural differences in the expression of pain behaviors. People from Western cultures are more permissive and pluralistic, they are believed that pain can be treated and controlled by doc- 
tors and pharmacists on the demand, whereas eastern cultures are more stoic and less acceptable of pain-related impairments (avoid pain medicines unless they are in severe pain). Ethnic background can affect the nature of health care offered to patients, including pain relief [30]. The present study was conducted in Indonesia, which is an eastern culture, where the culture is different from western countries.

Moreover, culture and spirituality play critical roles in labor pain in Muslim women. Beliefs and religious factors also play a significant role in attitudes toward childbirth pain [13] [23] [31]. The spiritual, religious and belief systems are the main aspects that shape a culture. The relation of culture to religiosity or spiritualties means that people experience and express spirituality in diverse ways based on their social and cultural worldviews that are composed of attitudes, values, concepts, and philosophies of life, because religion affects cultures. It has been linked to numerous communication traits and behaviors about health-related issues. In Islam, the mother who struggles against natural pain at that time deserves high appreciation from Allah to bestow upon her glorious and great rewards in the form of heaven [32] [33].

Muslims believe that health, illness, birth, life, and death all come from Allah. Thus, Muslim women do not perceive labor pain and illness as a form of punishment but rather as a way of atonement for one's sins, test of faith, and more importantly giving birth is glorious [32]. However, Muslims are encouraged to seek care or treatment and therapy during pain and illness [32] [33]. Therefore, understanding the level of labor pain in primiparous Muslim women in Indonesia in this study is a fundamental prerequisite if the nurse is to determine a nursing intervention in the form of pain relief techniques [34], and encourage them to choose spiritually and culturally acceptable coping methods in order to have a satisfactory birth [31] [34].

Moreover, it can be seen that many pain behaviors expressed by Indonesian Muslim women in response to labor pain in this study as Table 4, such as trying to control breathing, protection movement, crying, complaining of pain, and asking for help. Asking for help by saying praises to Allah, calling out Allah's name (Asma'aul husna), and reciting the Qur'an, sholawat (Table 5), were influenced by cultural and spiritual beliefs. This finding is similar to a study in Jordan which showed that deep breathing and walking were the most common methods in response to labor pain among Jordanian women, followed by screaming, crying, and spiritual coping methods such as praying, reading the Quran, and having confidence in God (Allah) [35]. A study in Turkey also reported that behaviors of women during labor were clenching anything with their fists, crying quietly or out loud, anxiousness, shouting, agitation, biting lips, change in facial expression, complaining, difficulty with self control, avoiding communication, and wandering [36]. Again, the mother's behavior appears influenced by cultural and spiritual beliefs. Therefore, it is necessary to develop a labor pain behaviors observation scale particular for Muslim women in the future. 
Table 5. Cultural pain behaviors $(n=42)$.

\begin{tabular}{ccc}
\hline Parameter of additional cultural pain behaviors & Frequency (n) & Percentage (\%) \\
\hline Praises to Allah & 28 & 66.66 \\
Saying Allah's name (Asmaul husna) & 11 & 26.19 \\
Reciting the Qur'an (short verses) & 1 & 2.38 \\
Sholawat & 2 & 4.76 \\
Total & 42 & 100 \\
\hline
\end{tabular}

\section{Conclusions}

The findings of this study showed that most first-time women experienced severe pain. Labor pain is unique for each individual because of the spiritual and cultural characteristics of women in labor that influence the neurophysiologic process of pain perception and pain tolerance illuminated by pain behaviors. They express spirituality in diverse ways of behaviors in response to the labor pain based on their cultures which are composed of attitudes, values, body movement, facial expression, communication and philosophies of life, because religion affects cultures. Efforts to know and acknowledge women's descriptions of pain from demographic and obstetric data are the key to enhance the provision of holistic competent nursing care.

This study has a limitation in generalization of the findings because it was carried out in the active phase of labor 3 - 4 centimeters of cervical dilation and in primiparous Muslim women. The findings were not covered all phases of labor pain.

\section{Recommendations and Implications}

Nurses should know the characteristics of women and how to guide the procedures according to a woman's cultural, ethnic, and belief systems in order to decrease labor pain. These findings can be used to determine nursing interventions and design appropriate programs or strategies for pregnant women and childbirth for Muslim women even with different backgrounds in culture, religion, and socioeconomic ethnic backgrounds. Therefore, a future study should be undertaken to determine the effects of demographic factors such as age, ethnicity, job, education, and socioeconomic status on labor pain. Also, the development of instruments on pain behaviors based on spiritual and cultural factors is needed. Further investigations in a large population are highly recommended to replicate the beneficial results of this study and use a more diverse population of Muslim and non-Muslim women from other countries in the world.

\section{Conflicts of Interest}

The authors declare no conflicts of interest regarding the publication of this paper. 


\section{References}

[1] Melzack, R., Kinch, R., Dobkin, P., Lebrun, M. and Taenzer, P. (1984) Severity of Labor Pain Influence of Physical as Well as Psychologic Variables. The Canadian Medical Association Journal, 130, 579-584.

[2] McCaffery, M. and Pasero, C. (1999) Assessment: Underlying Complexities, Misconceptions, and Practical Tools. In: McCaffery, M. and Pasero, C., Eds., Pain: Clinical Manual, 2nd Edition, Mosby, St. Louis, 35-102.

[3] Mander, R. (2011) Pain in Childbearing and Its Control: Key Issues for Midwives and Women. 2nd Edition, John Wiley \& Sons, Oxford.

[4] Smith, J.R. (2015) Management of the Third Stage of Labor. Medscape. http://emedicine.medscape.com/article/275304-overview

[5] Shrestha, I., Pradhan, N. and Sharma, J. (2013) Factors Influencing Perception of Labor Pain among Parturient Women at Tribhuvan University Teaching Hospital. Nepal Journal of Obstetrics and Gynecology (NJOG), 8, 26-30. https://doi.org/10.3126/njog.v8i1.8857

[6] Dengsangluri, J.A.S. (2015) Effect of Breathing Exercise in Reduction of Pain during First Stage of Labour among Primigravidas. International Journal of Health Sciences and Research, 5, 390-398.

[7] Sheiner, E., Sheiner, E.K. and Shoham-Vardi, I. (1998) The Relationship between Parity and Labor Pain. The International Journal of Gynecology \& Obstetrics, 63, 287-288. https://doi.org/10.1016/S0020-7292(98)00164-7

[8] Ikhsanuddin, A.H. (2007) Relationships among Pain Intensity, Pain Acceptance, and Pain Behaviors in Patients with Chronic Cancer Pain in Medan, Indonesia. Thesis, Prince of Songkla University, Songkhla, 103.

[9] Hsieh, A.Y., Tripp, D.A. and Ji, L.J. (2011) The Influence of Ethnic Concordance and Discordance on Verbal Reports and Nonverbal Behaviors of Pain. Pain, 152, 2016-2022. https://doi.org/10.1016/j.pain.2011.04.023

[10] Capogna, G., Camorcia, M., Stirparo, S., Valentini, G., Garassino, A. and Farcomeni, A. (2010) Multidimensional Evaluation of Pain during Early and Late Labor: A Comparison of Nulliparous and Multiparous Women. International Journal of $O b$ stetric Anesthesia, 19, 167-170. https://doi.org/10.1016/j.ijoa.2009.05.013

[11] Hall, W.A., Stoll, K., Hutton, E.K. and Brown, H. (2012) A Prospective Study of Effects of Psychological Factors and Sleep on Obstetric Interventions, Mode of Birth, and Neonatal Outcomes among Low-Risk British Columbian Women. BMC Pregnant \& Child, 12, 78-88. https://doi.org/10.1186/1471-2393-12-78

[12] El-Wahab, N. and Robinson, N. (2014) Analgesia and Anaesthesia in Labour. Obstetrics, Gynaecology and Reproductive Medicine, 24, 97-102. https://doi.org/10.1016/j.ogrm.2014.01.006

[13] Yual, V.I., Kaur, V. and Kaur, D. (2008) Programmed Labor for Optimizing Labor and Delivery. Science, 10, 62-64.

[14] Jantjes, L., Strumpher, J. and Kotze, W.J. (2007) The Experience of Childbrith in First-Time Mothers Who Received Narcotic Analgesics during the First Stage of Labour. Curationis, 30, 82-90. https://doi.org/10.4102/curationis.v30i2.1079

[15] Rakers, F., Bischoff, S., Schiffnes, R., Haase, M., Rupprecht, S., Kiehntopf, M., Kuhn-Velten, W.N., Schubert, H., Witte, O.W., Nijland, M.J., Nathanielsz, P.W. and Schwab, M. (2015) Role of Catecholamines in Maternal-Fetal Stress Transfer in Sheep. American Journal of Obstetrics and Gynecology, 213, 684.e1-9. https://doi.org/10.1016/j.ajog.2015.07.020 
[16] Rooks, J.P. (2012) Labor Pain Management Other than Neuroxial: What Do We Know and Where Do We Go Next? Birth, 39, 318-322. https://doi.org/10.1111/birt.12009

[17] Allameh, Z., Tehrani, H.G. and Ghasemi, M. (2015) Comparing the Impact of Acupuncture and Pethidine on Reducing Labor Pain. Advanced Biomedical Research, 4, 46. https://www.ncbi.nlm.nih.gov/pmc/articles/PMC4358033 https://doi.org/10.4103/2277-9175.151302

[18] Sakorntanun, W., Chatchawan, U. and Hongrattana, U. (2012) The Characteristics of Labor Pain during the Active Phase of Primipara. Journal of Medical Technology and Physical Therapy, 24, 191-200.

[19] Ministry of Health (2013) Maternal Health Services in Primary Health Facilities and Referral. Indonesia Ministry of Health, Jakarta.

[20] Aya, A.G.M., Vialles, N., Mangin, R., Robert, C., Ferrer, J.M., Ripart, J. and de La Coussaye, J.E. (2004) Chronobiology of Labour Pain Perception: An Observation Study. British Journal of Anaesthesia, 93, 451-453.

https://doi.org/10.1093/bja/aeh223

[21] Cunninghum, F.G., Leveno, K.J., Bloom, S.L., Hauth, J.C., Rouse, D.J. and Spong, C.Y. (2010) Williams Obstetrics. 23rd Edition, McGraw-Hill, New York.

[22] Desmawati and Cristie, P. (2009) Effect of Hypnotherapy in Reducing Postoperative Pain. Jurnal Bina Widya, 20, 21-24.

[23] Callister, L.C. and Khalaf, I. (2010) Spirituality in Childbearing Women. The Journal of Perinatal Education, 19, 16-17. https://doi.org/10.1624/105812410X495514

[24] Baosoung, C. (1984) Effects of Panned Instruction and Touch on Anxiety Reduction and Stress Coping Behavior during Labor. Master's Thesis, Mahidol University, Bangkok, 112.

[25] Taghizdeh, Z., Ebadi, A., Dehghani, M., Gharacheh, M. and Yadollahi, P. (2017) A Time for Psycho-Spiritual Transcendence: The Experiences of Iranian Women of Pain during Childbirth. Women and Birth, 30, 491-496. https://doi.org/10.1016/j.wombi.2017.04.010

[26] Lowderlmilk, D.L., Perry, S.E. and Cashion, K. (2014) Maternity Nursing. 8th Edition, Mosby, St. Louis.

[27] Anderson, K.O., Green, C.R. and Payne, R. (2009) Racial and Ethnic Disparities in Pain: Causes and Consequences of Unequal Care. The Journal of Pain, 10, 1187-204. https://doi.org/10.1016/j.jpain.2009.10.002

[28] Shavers, V.L., Bakos, A. and Sheppard, V.B. (2010) Race, Ethnicity, and Pain among the US Adult Population. Journal of Health Care for the Poor and Underserved, 21, 177-220. https://doi.org/10.1353/hpu.0.0255

[29] Molter, N. (2010) Alternative an Complimentary Therapies to Manage Labor Pain. Dissertation, Ball State University, Muncie, 2.

http://cardinalscholar.bsu.eduMolthttps://scholar.google.co.id/scholar?q=Molter\%2 C+N.+\%282010\%29.+Alternative+an+complimentary

[30] Lofvander, M.B. and Furhoff, A.K. (2012) Pain Behaviors in Young Immigrants Having Chronic Pain: An Exploratory Study in Primary Care. European Journal of Pain, 6, 123-132. https://doi.org/10.1053/eujp.2001.0309

[31] Abushaikha, L.A. (2007) Methods of Coping with Labor Pain Used by Jordanian Women. Journal of Transcultural Nursing, 18, 35-40. https://doi.org/10.1177/1043659606294194

[32] Muyassaro, P. (2012) Praying \& Dhikr to Pregnant Women and Labor. Al Magfirah, 
Jakarta.

[33] Aldossary, A., While, A. and Barribal, L. (2008) Health Care and Nursing in Saudi Arabia. International Nursing Review, 55, 125-128. https://doi.org/10.1111/j.1466-7657.2007.00596.x

[34] Sharareh, K. (2013) Outcomes Assessment of Pain Relief Techniques Use in Labour in Order to Increase Painless Normal Delivery. International Journal of Women's Health and Reproduction Sciences, 1, 1-5. https://doi.org/10.15296/ijwhr.2013.01

[35] Gallo, R.B.S., Santana, L.S., Ferreire, C.H.J., Marcolina, A.C., PoliNetto, O.B., Duarte, G. and Quintana, S.M. (2013) Massage Reduced Severity of Pain during Labour: A Randomised Trial. The Journal of Physiology, 59, 109-116. https://doi.org/10.1016/S1836-9553(13)70163-2

[36] Seda, U.E., Emre, Y. and Asli, G. (2017) Effects of Low Back Massage on Perceived Birth Pain and Satisfaction. Complementary Therapies in Clinical Practice, 28, 169-175. https://doi.org/10.1016/j.ctcp.2017.05.016 


\section{Appendix. Instruments}

\section{1) Visual Analogue Scale}

Direction: The lines below reflect the amount of labor pain scale (point to 100 mm VAS of Labor Pain Scale). Please you think about how much intense the physical feel or pain is in your abdomen during the last contraction. And then please mark anywhere on this line, which you think relevant with your feeling to show much of labor pain you are experiencing right now. This scale is a line that goes from no pain to the most pain imaginable.

- Please make your mark close to the right end, if you have a lot of pain.

- Please make your mark closer to the left end, if you do not have much pain.

- Please mark in the middle of the line, if you have a moderate of pain.

- Please mark your real amount labor pain right now on the next line. You may mark anywhere on the line (point to a picture):

$100 \mathrm{~mm}$ VAS of Labor Pain Scale

No pain

The most pain imaginable

\section{2) Pain Observation Behaviors Scale (POBS)}

(Researcher observe it same time as measurement of labor pain)

Direction: During uterine contraction, please consider and select the characteristics of the behaviors expressed by laboring women as shown follow:

\begin{tabular}{|c|c|c|c|c|c|c|}
\hline \multirow{2}{*}{ No } & \multirow{2}{*}{ Behavior } & \multicolumn{3}{|c|}{ Score } & \multicolumn{2}{|c|}{ Score } \\
\hline & & 3 & 2 & 1 & 1 & 23 \\
\hline & Vocalization & $\begin{array}{l}\text { Talking in normal } \\
\text { tone (good words) } \\
\text { or no sound }\end{array}$ & Sighing, moaning & $\begin{array}{l}\text { Crying out, } \\
\text { sobbing }\end{array}$ & & \\
\hline & $\begin{array}{c}\text { Body } \\
\text { movements }\end{array}$ & $\begin{array}{l}\text { Relaxed } \\
\text { movements }\end{array}$ & $\begin{array}{l}\text { Protection } \\
\text { movement }\end{array}$ & Restlessness & & \\
\hline & $\begin{array}{l}\text { Breathing } \\
\text { control }\end{array}$ & $\begin{array}{l}\text { Good regularly } \\
\text { control breathing }\end{array}$ & $\begin{array}{l}\text { Irregularly but try } \\
\text { to control breathing }\end{array}$ & $\begin{array}{c}\text { Cannot } \\
\text { control breathing }\end{array}$ & & \\
\hline & $\begin{array}{c}\text { Facial } \\
\text { expression }\end{array}$ & Relaxed, neutral & Tense & Grimacing & & \\
\hline & Communication & $\begin{array}{l}\text { No complaints } \\
\text { of pain }\end{array}$ & $\begin{array}{l}\text { Some complaints of } \\
\text { pain or asking for } \\
\text { help (to God or other) }\end{array}$ & $\begin{array}{l}\text { Desperate or often } \\
\text { asking for help }\end{array}$ & & \\
\hline & & & POBS & & & \\
\hline
\end{tabular}

